\title{
The Importance of Feedback in Relation to Doing Practical Teaching Exercises. Opinions Postgraduate Student School of Pedagogical and Technological Education Heraklio of Crete
}

\author{
Iosif Fragoulis ${ }^{1} \&$ Elli Diamantaki ${ }^{2}$ \\ ${ }^{1}$ School of Pedagigical and Technological Education, Krete, Greece \\ ${ }^{2}$ Graduate of Political Science faculty, MSc in Political Science, Iraklion of Crete, Greece \\ Correspondence: Iosif Fragoulis, School of Pedagogical and Technological Education, Sokratous 18 \\ Kastelokabos, zc.26504, Patras, Greece. Tel: 30-261-091-0066. E-mail: sfaka@otenet.gr
}

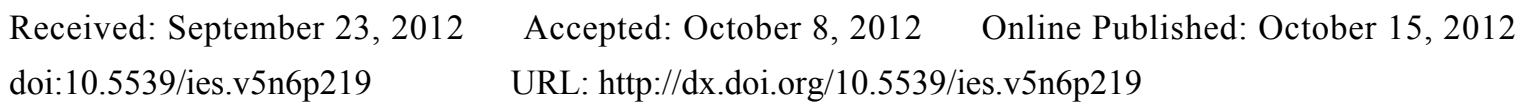

\begin{abstract}
In this essay are introduced the aspects of scholars of the Annual Programme of Pedagogical Training of ASPAITE in Iraklio of Crete in relation to feedback they receive by their teachers and their co-scholars during the pragmatic teaching exercises. In the $1^{\text {st }}$ part of our essay, the meaning of feedback during the P.T.E. is analyzed. It is presented the operational framework of P.T.E. and is described the methodology of their realization. In the $2^{\text {nd }}$ part of the essay, the research transaction methodology is described. In particular, are presented the aim, the research queries, the sample population, the restrictions as well as the tool of collecting data. In the $3^{\text {rd }}$ part of the essay, the most significant results and conclusions are presented.
\end{abstract}

Keywords: practical teaching exercises, feedback, opinions postgraduate student, educational team

\section{Introduction}

Feedback is extremely important in relation to doing Practical Teaching Exercises as it notifies the academics regarding the achievement of their teaching intervention's aims not only in a planning and doing level but also in a level of appraise the teaching intervention.

Furthermore, it contributes to the effective learning and the development of critic contemplation (Giannakopoulou, 2008:13). In relation to feedback, the advantages and disadvantages of Practical Teaching Exercises are observed and ways of improving the Teaching intervention are suggested (Platsidou, 2012: 100). The feedback procedure is based on the supervisor- consultant and the members of the contrainees' team.

Feedback refers to various messages (visual, audio, verbal, non-verbal) which are received by the trainee regarding the results of the teaching actions. In addition, it contributes to the acknowledgement of the strong points of the teaching interference as well as the detection of weak points in order to improve them.

\section{The Feedback Meaning in the Practical Teaching Exercises}

The feedback meaning is well known from the state area where it confirms the mechanism which informs the operator with the result of its actions and directs its operations (Platsidou, 2012: 100). It usually has two types: the positive and the negative. The positive motivates the system in order to increase its operations whereas the negative leads to the interval of its operations so as to keep its stability (Kapsalis, 2006).

In the field of teaching, feedback constitutes an element for the exercise of the teaching skills. It contributes to the detection of positive characteristics of the teaching interference as well as the detection of the weak ones in order to improve them. Lack of feedback entails no improvement of the trainees' progress or their skills' development (Lerner, 2002; Kapsalis, 2006).

Feedback can be achieved either by the supervisor- consultant or by the trainee himself or by the trainee's team (Platsidou, 2012: 100). Each one of them has composed a survey object since 1970, all of which end up in the same result: no kind of feedback suffices by itself as to motivate the procedures of improving the teaching exercises of a teacher (Giannakopoulou, 2008:13). An overall approach is needed to the procedure of feedback which is provided by everyone namely the supervisor- consultant, the trainee and its team. 
In order to be effective, feedback has to be composed by sufficiency, quality, imminence and be realized in a suitable way (Day, 1995).

Feedback contributes to the emergence of critical thought as a cognitive procedure in the Pragmatic Teaching Exercises. (Giannakopoulou, 2008:13). It should take place in each part of the teaching intervention (e.g. introduction, set goals, content, educational techniques, use of speaking, body language, team contact, evaluation etc). It should also be comprehensive in order to give the opportunity to the trainee to realize the strong or the weak points of his teaching method and furthermore be capable to do the necessary improvements. It is essential this procedure to take place in such a way that the trainee's personality and validity should not be affected. It is significant to be emphasized the "product" a trainee produces and not the trainee as a personality who is accepted by the team (Fragoulis, 2011).

According to the previous premises it helps the teacher to improve his teaching pragmatics. New technologies contribute in a great extent as each teaching interference is recorded and then next in sequence is the analysis and edit (Cornford, 1991).

\section{Practical Teaching Exercises' Operational Frame}

Pragmatic Teaching Exercises constitute a significant part of teachers' education not only during their studies in the academic courses but also in A.S.PAI.T.E. (School of Pedagogical and Technological Education). During their concept teachers have the opportunity to implement the knowledge they earned at the theoretical class of their courses.

Practical Teaching Exercises in School of Education and A.S.PAI.T.E., with little differences per course, constitute microteachings, preliminary teachings, attending and teaching to specific schools, in subjects related to the scholars' expertise (Hatzidimou, 1997: 58-59).

They are held in small groups of 4-5 people and provide the candidates the capacity to improve the method of planning, concept and evaluate their teaching, their teaching techniques. During the previous procedure the role of the supervisor is significant who acts as a mentor for the educational team (University of Patras, School of Primary Education, Teaching Guide, 2008: 25).

Practical teaching exercises aim to the incorporation of theory into action demonstrating that teaching is a procedure unformulaic which needs scheduling, planning and preparing in a safe and controlled environment (laboratory of Practical Teaching Exercises). They help the scholars create learning environments in which authentic knowledge is produced (A.S.PAI.T.E., Laboratory Guide P.T.E, 2012).

The educational team works in a supportive way in order to expound its skills and consultants-supervisors work with a common frame of reference in their teams as to insure similarity in the teaching method of candidate teachers. During the function of the educational team, candidates have the opportunity to meditate by the end of their teaching and reconsider -if necessary- their methological choices and the guidelines they followed. The whole procedure is a strong learning procedure during which research elements are evaluated. These elements are determined from action- observation- thought- reconsideration (Carr \& Kemmis, 1997; Bagakis, 2002).

\section{Research Method}

\subsection{Aim Research}

The aim of the research is to list the teachers' aspects concerning the feedback role they receive from the supervisor- consultant and the other members of the team during the Practical Teaching Exercises of the annual Programme of Pedagogic Training of A.S.PAI.T.E.

\subsection{Research Questions}

Do scholars' aspects about feedback they receive from teaching preparation- planning depend on their demographic characteristics?

Do scholars' aspects about feedback they receive from teaching content depend on their demographic characteristics?

Do scholars' aspects about feedback they receive from teaching transaction depend on their demographic characteristics?

Do scholars' aspects about feedback they receive from the choice of suitable educational techniques and means of teaching depend on their demographic characteristics?

Do scholars' aspects about feedback they receive from the formation of proper environment with their students depend on their demographic characteristics? 
Do scholars' aspects about feedback they receive from their teaching interference's evaluation depend on their demographic characteristics?

\subsection{Population - Research Sample - Research Restrictions}

The sample of the research was consisted of 50 scholars of A.S.PAI.T.E.'s annex in Heraklio of Crete who attended the annual Programme of Pedagogic Training during 2011- 2012. The research was carried out in AprilMay.

The research took place in a particular sample of the scholars and as a result its results cannot be representative for the whole scholar community of A.S.PAI.T.E.

\subsection{Tools of Collecting Data}

The tool which was used to collect data was the questionnaire as it allowed the collection of a big amount of them in a short period of time. If another technique was used such an effort would be time consuming because of the large number of scholars and the investigator's limited time (Dimitropoulos, 2001:210). The combination of closed questions offered the ability to collect the necessary quantity elements for the research transaction (Cohen \& Manion, 1997:140 -141; Kyriazi, 1999:127-131).

\subsection{Statistic Edit}

The questionnaires were reformed by using SPSS (v.17) which is widely used in the social science.

\section{Presentation of Results}

\subsection{Demographic Characteristics}

As far as the demographic elements of the subjects' research we observe the followings:

In relation to gender:

15 out of 50 were men $(30 \%)$ and 35 out of 50 were women (30\%).

In relation to age:

38 out of 50 were between $25-34$ years old (76\%) and 11 out of 50 were between $35-44$ years old $(22 \%)$ and 1 out of 50 was more than 44 years old $(2 \%)$.

Table 1. Allocation related to age

\begin{tabular}{lrc}
\hline Age 25-34 & 38 & $76 \%$ \\
\hline Age 36-45 & 11 & $22 \%$ \\
$>\quad 45$ & 1 & $2 \%$ \\
Total & $\mathbf{5 0}$ & $\mathbf{1 0 0 \%}$ \\
\hline
\end{tabular}

\section{In relation to expertise:}

19 out of 50 had graduated from computer science course (38\%), 10 out of 50 had graduated from economics and low courses (20\%), 9 out of 50 had graduated from school of medicine (18\%), 4 out of 50 had graduated from agricultural courses $(8 \%)$ and 8 out of 50 were mechanics $(16 \%)$.

In relation to teaching experience:

30 out of $50(64 \%)$ had a previous teaching experience for almost one year, 16 out of $50(32 \%)$ had teaching experience of approximately $2-5$ years, 4 out of $50(8 \%)$ had no teaching experience.

In relation to postgraduate programmes:

44out of $50(64 \%)$ had attended a postgraduate programme, 2 out of $50(4 \%)$ had Phd and 4out of $50(8 \%)$ had not attended a postgraduate programme.

5.2 Scholars' Aspects in Relation to the Feedback They Receive from the Preparation -planning of Their Teaching

In relation to the question "Did the feedback, you receive from the supervisor and your colleagues, help you choose the suitable teaching object?" according to the results of the univariate analysis we realize the followings: 16/50 (32\%) answered "very much", 14/50 (28\%) answered "much", 16/50 (32\%) replied "enough", 4/50 (8\%) replied "few". According to the bivariate analysis, with check of criteria $\mathrm{x}^{2}$, significant statistic discrepancies 
(a 0.05$)$ were observed in their answers in relation to their age $(\mathrm{p}=0.000)$ and the ages of teaching experience $(\mathrm{p}=0.001)$.

Table 2. Feedback of P.T.E. and proper choice of teaching object

\begin{tabular}{lrl}
\hline VERY MUCH & 16 & $32 \%$ \\
\hline MUCH & 14 & $28 \%$ \\
ENOUGH & 16 & $32 \%$ \\
FEW & 4 & $8 \%$ \\
TOTAL & $\mathbf{5 0}$ & $\mathbf{1 0 0 \%}$ \\
\hline
\end{tabular}

In relation to research subjects' aspects to the question "Did the feedback, you receive from the supervisor and your colleagues during P.T.E., help you as to completely set the aim and the targets of your teaching interference?" according to the univariate analysis we realize the followings: $16 / 50$ (32\%) replied "v.much", 22/50 (44\%) replied "much", 8/50 (16\%) replied "enough", 4/50 (8\%) replied "few". According to the bivariate analysis, with check of criteria $x^{2}$, significant statistic discrepancies $(a<0.05)$ were observed in their answers in relation to their gender $(\mathrm{p}=0.000)$, age $(\mathrm{p}=0.001)$ and the ages of teaching experience $(\mathrm{p}=0.001)$.

In relation to research subjects' aspects to the question "Did the feedback, you receive from the supervisor and your colleagues during P.T.E., help you as to choose the proper teaching method?" according to the univariate analysis we realize the followings: 26/50 (52\%) replied "v.much", 20/50 (40\%) replied "much", 4/50 (18\%) replied "enough". According to the bivariate analysis, with check of criteria $\mathrm{x}^{2}$, significant statistic discrepancies $(a<0.05)$ were observed in their answers in relation to their age $(\mathrm{p}=0.001)$ and the ages of teaching experience $(\mathrm{p}=0.002)$.

Table 3. Feedback of P.T.E. and proper choice of teaching methods

\begin{tabular}{lrl}
\hline VERY MUCH & 26 & $52 \%$ \\
\hline MUCH & 20 & $40 \%$ \\
ENOUGH & 4 & $8 \%$ \\
TOTAL & $\mathbf{5 0}$ & $\mathbf{1 0 0 \%}$ \\
\hline
\end{tabular}

In relation to research subjects' aspects to the question "Did the feedback, you receive from the supervisor and your colleagues during P.T.E., help you as to organize properly your teaching activities?" according to the univariate analysis we realize the followings: $20 / 50$ (40\%) replied "v.much", 18/50 (36\%) replied "much", 12/50 replied "enough". According to the bivariate analysis, with check of criteria $x^{2}$, significant statistic discrepancies $(\mathrm{a}<0.05)$ were observed in their answers in relation to the ages of teaching experience $(\mathrm{p}=0.002)$.

\subsection{Scholars' Aspects as to the Feedback They Receive in Relation to Choose Their Teaching Content}

In relation to research subjects' aspects to the question "Did the feedback, you receive from the supervisor and your colleagues during P.T.E., help you as to adjust your teaching intervention's content to your students' needs?" according to the univariate analysis we realize the followings: 16/50 (32\%) replied "v.much", 22/50 (44\%) replied "much", 12/50 (24\%) replied "enough". According to the bivariate analysis, with check of criteria $\mathrm{x}^{2}$, significant statistic discrepancies (a 0.05 ) were observed in their answers in relation to the ages of teaching experience $(\mathrm{p}=0.001)$.

Table 4. Feedback of P.T.E. and adjustment the teaching content to students' needs

\begin{tabular}{lll}
\hline VERY MUCH & 16 & $32 \%$ \\
\hline MUCH & 22 & $44 \%$ \\
ENOUGH & 12 & $24 \%$ \\
TOTAL & $\mathbf{5 0}$ & $\mathbf{1 0 0 \%}$ \\
\hline
\end{tabular}


In relation to research subjects' aspects to the question "Did the feedback, you receive from the supervisor and your colleagues during P.T.E., help you as to adjust your teaching contents to your students' special features?" according to the univariate analysis we realize the followings: $24 / 50$ (48\%) replied "v.much", 14/50 (28\%) replied "much", 12/50 (24\%) replied "enough". According to the bivariate analysis, with check of criteria $\mathrm{x}^{2}$, significant statistic discrepancies (a 0.05 ) were observed in their answers in relation to the ages of teaching experience $(\mathrm{p}=0.001)$.

In relation to research subjects' aspects to the question "Did the feedback, you receive from the supervisor and your colleagues during P.T.E., help you as to adjust your teaching intervention's content to your students' cognitive level?" according to the univariate analysis we realize the followings: 14/50 (28\%) replied "v.much", $32 / 50(64 \%)$ replied "much", 4/50 (8\%) replied "enough". According to the bivariate analysis, with check of criteria $\mathrm{x}^{2}$, significant statistic discrepancies (a 0.05$)$ were observed in their answers in relation to their age $(\mathrm{p}=0.001)$ and the ages of teaching experience $(\mathrm{p}=0.002)$.

In relation to research subjects' aspects to the question "Did the feedback, you receive from the supervisor and your colleagues during P.T.E., help you as to adjust your teaching content to your students' rate of participation during the teaching?" according to the univariate analysis we realize the followings: $26 / 50(52 \%)$ replied "v.much", 20/50 (40\%) replied "much", 4/50 (8\%) replied "enough". According to the bivariate analysis, with check of criteria $\mathrm{x}^{2}$, significant statistic discrepancies (a 0.05$)$ were observed in their answers in relation to their age $(\mathrm{p}=0.002)$ and the ages of teaching experience $(\mathrm{p}=0.000)$.

Table 5. Feedback of P.T.E. and adjustment the teaching content to students' rate of participation

\begin{tabular}{lll}
\hline VERY MUCH & 26 & $52 \%$ \\
\hline MUCH & 20 & $40 \%$ \\
ENOUGH & 4 & $8 \%$ \\
TOTAL & $\mathbf{5 0}$ & $\mathbf{1 0 0 \%}$ \\
\hline
\end{tabular}

\subsection{Scholars' Aspects as to the Feedback They Receive in Relation to Have Their Teachings}

In relation to research subjects' aspects to the question "Did the feedback, you receive from the supervisor and your colleagues during P.T.E., help you so that your students participate vigorously during the lesson?" according to the univariate analysis we realize the followings: 22/50 (44\%) replied "v.much", 16/50 (32\%) replied "much", 12/50 (24\%) replied "enough". According to the bivariate analysis, with check of criteria $\mathrm{x}^{2}$, significant statistic discrepancies (a 0.05$)$ were observed in their answers in relation to their age $(\mathrm{p}=0.001)$ and the ages of teaching experience $(\mathrm{p}=0.000)$.

In relation to research subjects' aspects to the question "Did the feedback, you receive from the supervisor and your colleagues during P.T.E., help you so that you achieve better linking between the curriculum and the teaching targets?" according to the univariate analysis we realize the followings: 20/50 (40\%) replied "v.much", 26/50 (52\%) replied "much", 4/50 (8\%) replied "enough".

Table 6. Feedback of P.T.E. and linking between the curriculum and the teaching targets

\begin{tabular}{lll}
\hline VERY MUCH & 20 & $40 \%$ \\
\hline MUCH & 26 & $52 \%$ \\
ENOUGH & 4 & $8 \%$ \\
TOTAL & $\mathbf{5 0}$ & $\mathbf{1 0 0 \%}$ \\
\hline
\end{tabular}

In relation to research subjects' aspects to the question "Did the feedback, you receive from the supervisor and your colleagues during P.T.E., help you so that you achieve proper linking between theory and action?" according to the univariate analysis we realize the followings: 10/50 (20\%) replied "v.much", 32/50 (64\%) replied "much", $8 / 50(16 \%)$ replied "enough". According to the bivariate analysis, with check of criteria $x^{2}$, significant statistic discrepancies (a 0.05 ) were observed in their answers in relation to their ages of teaching experience $(\mathrm{p}=0.000)$.

In relation to research subjects' aspects to the question "Did the feedback, you receive from the supervisor and your colleagues during P.T.E., help you so that you achieve better learning results?" according to the univariate analysis we realize the followings: 24/50 (48\%) replied "v.much", 12/50 (24\%) replied "much", 8/50 (16\%) 
replied "enough", 6/50 (12\%) replied "few". According to the bivariate analysis, with check of criteria $\mathrm{x}^{2}$, significant statistic discrepancies (a 0.05) were observed in their answers in relation to their age $(p=0.002)$ and the ages of teaching experience $(\mathrm{p}=0.000)$.

Table 7. Feedback of P.T.E. and achieving better learning results

\begin{tabular}{lll}
\hline VERY MUCH & 24 & $48 \%$ \\
\hline MUCH & 12 & $24 \%$ \\
ENOUGH & 8 & $16 \%$ \\
FEW & 6 & $12 \%$ \\
TOTAL & $\mathbf{5 0}$ & $\mathbf{1 0 0 \%}$ \\
\hline
\end{tabular}

5.5 Scholars' Aspects as to the Feedback They Receive in Relation to the Choice of Proper Educational Techniques and Means of Teaching

In relation to research subjects' aspects to the question "Did the feedback, you receive from the supervisor and your colleagues during P.T.E., help you so that you choose proper, in relation to the teaching content, educational techniques?" according to the univariate analysis we realize the followings: 16/50 (32\%) replied "v.much", 22/50 (44\%) replied "much", 24/50 (24\%) replied "enough". According to the bivariate analysis, with check of criteria $\mathrm{x}^{2}$, significant statistic discrepancies (a 0.05$)$ were observed in their answers in relation to their age $(\mathrm{p}=0.001)$ and the ages of teaching experience $(\mathrm{p}=0.000)$.

In relation to research subjects' aspects to the question "Did the feedback, you receive from the supervisor and your colleagues during P.T.E., help you so that you use properly educational techniques?" according to the univariate analysis we realize the followings: 18/50 (36\%) replied "v.much", 28/50 (56\%) replied "much", 4/50 $(8 \%)$ replied "enough". According to the bivariate analysis, with check of criteria $\mathrm{x}^{2}$, significant statistic discrepancies (a 0.05) were observed in their answers in relation to their age $(p=0.001)$ and the ages of teaching experience $(\mathrm{p}=0.002)$.

Table 8. Feedback of P.T.E. and achieving better use educational techniques

\begin{tabular}{lrl}
\hline VERY MUCH & 18 & $36 \%$ \\
\hline MUCH & 28 & $56 \%$ \\
ENOUGH & 4 & $16 \%$ \\
TOTAL & $\mathbf{5 0}$ & $\mathbf{1 0 0 \%}$ \\
\hline
\end{tabular}

In relation to research subjects' aspects to the question "Did the feedback, you receive from the supervisor and your colleagues during P.T.E., help you so that you choose properly supervising means of teaching in relation to the teaching object?" according to the univariate analysis we realize the followings: 26/50 (52\%) replied "v.much", 20/50 (40\%) replied "much", 4/50 (8\%) replied "enough". According to the bivariate analysis, with check of criteria $\mathrm{x}^{2}$, significant statistic discrepancies (a 0.05 ) were observed in their answers in relation to gender $(p=0.001)$, their age $(p=0.000)$ and the ages of teaching experience $(p=0.002)$.

In relation to research subjects' aspects to the question "Did the feedback, you receive from the supervisor and your colleagues during P.T.E., help you so that you choose properly supervising means of teaching in relation to the teaching object?" according to the univariate analysis we realize the followings: 26/50 (52\%) replied "v.much", 20/50 (40\%) replied "much", 4/50 (8\%) replied "enough". According to the bivariate analysis, with check of criteria $\mathrm{x}^{2}$, significant statistic discrepancies (a 0.05 ) were observed in their answers in relation to gender $(p=0.001)$, their age $(p=0.000)$ and the ages of teaching experience $(p=0.002)$.

In relation to subjects' aspects to the question "Did the feedback, you receive from the supervisor and your colleagues during P.T.E., help you so that you use properly the supervising means of teaching?" according to the univariate analysis we realize the followings: 20/50 (40\%) replied "v.much", 22/50 (44\%) replied "much", $8 / 50(16 \%)$ replied "enough". According to the bivariate analysis, with check of criteria $x^{2}$, significant statistic discrepancies (a 0.05) were observed in their answers in relation to gender $(p=0.001)$, their age $(p=0.000)$ and the ages of teaching experience $(\mathrm{p}=0.001)$.

In relation to research subjects' aspects to the question "Did the feedback, you receive from the supervisor and your colleagues during P.T.E., help you so that you use contemporary supervising means of teaching?" 
according to the univariate analysis we realize the followings: $22 / 50$ (44\%) replied "v.much", 18/50 (36\%) replied "much", 10/50 (20\%) replied "enough". According to the bivariate analysis, with check of criteria $\mathrm{x}^{2}$, significant statistic discrepancies (a 0.05) were observed in their answers in relation to their age $(\mathrm{p}=0.001)$ and the ages of teaching experience $(\mathrm{p}=0.002)$.

Table 9. Feedback of P.T.E. and use of contemporary supervising means of teaching

\begin{tabular}{lll}
\hline VERY MUCH & 22 & $44 \%$ \\
\hline MUCH & 18 & $36 \%$ \\
ENOUGH & 10 & $20 \%$ \\
TOTAL & $\mathbf{5 0}$ & $\mathbf{1 0 0 \%}$ \\
\hline
\end{tabular}

5.6 Scholars' Aspects as to the Feedback They Receive in Relation to the Creation of a Proper Environment of Communication with the Students

In relation to research subjects' aspects to the question "Did the feedback, you receive from the supervisor and your colleagues during P.T.E., help you so that you create an equal relation with students?" according to the univariate analysis we realize the followings: $24 / 50$ (48\%) replied "v.much", 16/50 (32\%) replied "much", 10/50 (20\%) replied "enough". According to the bivariate analysis, with check of criteria $\mathrm{x}^{2}$, significant statistic discrepancies (a 0.05) were observed in their answers in relation to gender $(p=0.001)$, their age $(p=0.00)$ and the ages of teaching experience $(\mathrm{p}=0.003)$.

In relation to research subjects' aspects to the question "Did the feedback, you receive from the supervisor and your colleagues during P.T.E., help you so that you create a sincere relation with students?" according to the univariate analysis we realize the followings: 36/50 (72\%) replied "v.much", 4/50 (8\%) replied "much", 10/50 $(20 \%)$ replied "enough". According to the bivariate analysis, with check of criteria $\mathrm{x}^{2}$, significant statistic discrepancies (a 0.05) were observed in their answers in relation to gender $(p=0.001)$, their age $(p=0.000)$ and the ages of teaching experience $(\mathrm{p}=0.000)$.

Table 10. Feedback of P.T.E. and creation of sincere relations with students

\begin{tabular}{lll}
\hline VERY MUCH & 36 & $72 \%$ \\
\hline MUCH & 4 & $8 \%$ \\
ENOUGH & 10 & $20 \%$ \\
TOTAL & $\mathbf{5 0}$ & $\mathbf{1 0 0 \%}$ \\
\hline
\end{tabular}

In relation to research subjects' aspects to the question "Did the feedback, you receive from the supervisor and your colleagues during P.T.E., help you so that you urge the team ambiance of communication?" according to the univariate analysis we realize the followings: 28/50 (56\%) replied "v.much", 14/50 (28\%) replied "much", $8 / 50(16 \%)$ replied "enough". According to the bivariate analysis, with check of criteria $\mathrm{x}^{2}$, significant statistic discrepancies (a 0.05) were observed in their answers in relation to gender $(p=0.000)$, their age $(p=0.001)$ and the ages of teaching experience $(\mathrm{p}=0.001)$.

In relation to research subjects' aspects to the question "Did the feedback, you receive from the supervisor and your colleagues during P.T.E., help you so that you overhaul the conflicts in the educational team?" according to the univariate analysis we realize the followings: 25/50 (50\%) replied "v.much", 17/50 (34\%) replied "much", $8 / 50(16 \%)$ replied "enough". According to the bivariate analysis, with check of criteria $x^{2}$, significant statistic discrepancies (a 0.05) were observed in their answers in relation to gender $(p=0.001)$, their age $(p=0.00)$ and the ages of teaching experience $(\mathrm{p}=0.003)$.

Table 11. Feedback of P.T.E. and prevention of students' conflicts

\begin{tabular}{lll}
\hline VERY MUCH & 25 & $50 \%$ \\
\hline MUCH & 17 & $34 \%$ \\
ENOUGH & 8 & $16 \%$ \\
TOTAL & $\mathbf{5 0}$ & $\mathbf{1 0 0 \%}$ \\
\hline
\end{tabular}




\subsection{Scholars' Aspects as to the Feedback They Receive in Relation to Have Their Teachings}

In relation to research subjects' aspects to the question "Did the feedback, you receive from the supervisor and your colleagues during P.T.E., help you so that you think in a critical way in relation to your teaching planning?" according to the univariate analysis we realize the followings: 18/50 (36\%) replied "v.much", 24/50 (48\%) replied "much", 4/50 (8\%) replied "enough", 4/50 (8\%) replied "few". According to the bivariate analysis, with check of criteria $\mathrm{x}^{2}$, significant statistic discrepancies (a 0.05$)$ were observed in their answers in relation to their age $(\mathrm{p}=0.000)$ and the ages of teaching experience $(\mathrm{p}=0.000)$.

Table 12. Feedback of P.T.E. and critical thought during the teaching planning

\begin{tabular}{lll}
\hline VERY MUCH & 18 & $36 \%$ \\
\hline MUCH & 24 & $48 \%$ \\
ENOUGH \& FEW & 8 & $16 \%$ \\
TOTAL & $\mathbf{5 0}$ & $\mathbf{1 0 0 \%}$ \\
\hline
\end{tabular}

In relation to research subjects' aspects to the question "Did the feedback, you receive from the supervisor and your colleagues during P.T.E., help you so that you think in a critical way in relation to your methodological choices?" according to the univariate analysis we realize the followings: 20/50 (40\%) replied "v.much", 22/50 (44\%) replied "much", 6/50 (8\%) replied "enough", 2/50 (4\%) replied "few". According to the bivariate analysis, with check of criteria $\mathrm{x}^{2}$, significant statistic discrepancies (a 0.05 ) were observed in their answers in relation to their age $(\mathrm{p}=0.000)$ and the ages of teaching experience $(\mathrm{p}=0.002)$.

Table 13. Feedback of P.T.E. and critical thought in relation to methodological choices

\begin{tabular}{lll}
\hline VERY MUCH & 20 & $40 \%$ \\
\hline MUCH & 22 & $44 \%$ \\
ENOUGH & 6 & $12 \%$ \\
FEW & 2 & $4 \%$ \\
TOTAL & $\mathbf{5 0}$ & $\mathbf{1 0 0} \%$ \\
\hline
\end{tabular}

In relation to research subjects' aspects to the question "Did the feedback, you receive from the supervisor and your colleagues during P.T.E., help you so that you think in a critical way in relation to the extent you achieve the goals of the teaching?" according to the univariate analysis we realize the followings: $26 / 50(52 \%)$ replied "v.much", 12/50 (24\%) replied "much", 8/50 (16\%) replied "enough", 4/50 (8\%) replied "few". According to the bivariate analysis, with check of criteria $\mathrm{x}^{2}$, significant statistic discrepancies (a 0.05$)$ were observed in their answers in relation to their age $(\mathrm{p}=0.001)$ and the ages of teaching experience $(\mathrm{p}=0.000)$.

In relation to research subjects' aspects to the question "Did the feedback, you receive from the supervisor and your colleagues during P.T.E., help you so that you think in a critical way in relation to the acknowledgement of strong and weak points of your teaching?" according to the univariate analysis we realize the followings: $24 / 50$ (48\%) replied "v.much", 16/50 (32\%) replied "much", 10/50 (20\%) replied "enough". According to the bivariate analysis, with check of criteria $\mathrm{x}^{2}$, significant statistic discrepancies (a 0.05 ) were observed in their answers in relation to their age $(\mathrm{p}=0.000)$ and the ages of teaching experience $(\mathrm{p}=0.000)$.

\section{Conclusion}

According to the research results we realize that the scholars regard that the feedback they receive during the P.T.E. from the supervisor and the colleagues help them in a great extent to choose the teaching object correctly, to define the purpose and the targets of their teaching interference with clarity and accuracy, to choose the teaching methods correctly and organize their teaching activities in a better way. This aspect is mainly supported by the participants aged between 25- 34 and with teaching experience between 2-5 years. These participants realize the importance of feedback to choose teaching object, to the right planning of their teaching, to the choice of proper teaching methods and to the organization of their teaching activities.

According to the research results it is realized that the subjects of the survey assume in a great extent that the feedback they receive during the P.T.E. from the supervisor and the colleagues during their teachings, help so that they customize their teaching level to their students' needs and characteristics, their content and teaching rate to their students' cognitive level, to urge their students participate more during the teaching, the linking 
between theory and action so as to achieve better learning results. This aspect is mainly supported by the participants aged between 25-34 and with teaching experience between 2-5 years. These participants realize the importance of customizing their teaching according to their students' needs and characteristics for the purpose of urging their students participate more during the teaching and furthermore, linking between theory and action.

According to the research it is realized that the scholars assume in a great extent that the feedback they receive from the supervisor and their colleagues during their teachings, help so that they choose the proper, in relation to their content of teaching, educational techniques and supervising means of teaching and use them in an effective way. This aspect is mainly supported by the participants aged between 25- 34 and those who have teaching experience between 2-5 years. It is obvious that thanks to the teaching experience they already have, they can realize that the function of proper educational techniques while being supported by the function of proper teaching supervising means contribute to the achievement of teaching interference's objective.

According to the research it is realized that the scholars assume in a great extent that the feedback they receive from the supervisor and their colleagues during their teachings, help so that they create an equal and sincere relation with their students, they create a team ambiance of communication and cooperation and they overhaul the conflicts in the educational team. This aspect is mainly supported by the participants aged between 25- 34 and those who have teaching experience between 2-5 years. These subjects realize the significance of equal and sincere relation among the team members not only for the achievement of the goals but also for its effective working.

According to the research results it is realized that the subjects of the survey assume in a great extent that the feedback they receive during the P.T.E. from the supervisor and the colleagues during their teachings, help so that they think in a critical way in relation to the planning and realization of their teachings as well as the degree of achievement of their teaching interference's goals. This aspect is mainly supported by the participants aged between 25- 34 and those who have teaching experience between 2-5 years. These subjects realize the significance of critical thought during planning, organization, realization, and evaluation of their teaching intervention.

To sum up, we could argue that feedback is effective only when it is substantiated with meticulous and systematic way and aim at the enhancement of pragmatic teaching and behavior. To accomplish its goal it is essential the proper planning, organization and realization of teaching intervention. It is also essential to be looked for by the teacher and regard it as a tool of improving his teaching techniques as well as his business development.

\section{References}

Bagakis, G. (2002). Teacher as an investigator. Athens: Metaixmio (In Greek).

Carr, W., \& Kemmis, S. (1997). For a Critical Educational Theory. Athens: Kodikas (In Greek).

Cohen, L., \& Manion, L. (1997). Educational Research Methodology. Athens: Metexmio (In Greek).

Conford, R. (1991). Microteaching Skill Generalization and Transfer: Training Preservice Teachers in Introductory Lesson Skills. Teaching and Teacher Education, 7, 25-56. http://dx.doi.org/10.1016/0742-051X(91)90056-U

Day, K. (1995). Feedback on teaching, in: F. Forester, D. Hounsell \& S. Thompson (Eds.), Teaching tutoring and demo straining: A handbook (pp.79-88). Edinbourgh: Centre for Teaching, Learning and Assesment.

Dimitropoulos, E. (1998). Teachers and their profession, Contribution in the development of a Greek teacher's professional psychology. Athens: Grigoris (In Greek).

Fragoulis, J. (2011). Practical teaching exercises, Teaching Notes, School of Pedagogical and Technological Education (In Greek).

Giannakopoulou, E. (2008). Microteaching in education of adults' instructor: From feedback to reflection. Adult education, 14, 11-15 (In Greek).

Kapsalis. A. (2006). Pedagogical Psychology. Thessaloniki: Kyriakidis (In Greek).

Kyriazi, N. (1999). Sociological Research. Critical overview of methods and techniques. Athens: Ellinika Grammata (In Greek).

Lerner, M. (2002). Concepts and theories of human development. Erlbaum: Mahwah.

Platsidou, M. (2010). The implementation of feedback in teaching. Inspection of Educational issues, 16, 101-113, Athens: Pedagogical Institute (In Greek). 
School of Pedagogical and Technological Education. (2012). P.T.E Laboratory Guide. Athens: ASPAITE (In Greek).

University of Patras, Department of primary education. (2008). Study guide. Patra: University of Patras (In Greek).

Xatzidimou, D. (1997). Microteaching in teachers' education. A theoretical and empirical approach. Thessaloniki: Kyriakidis (In Greek). 